Clinical Research Paper

\title{
Integration of stereotactic radiotherapy in the treatment of metastatic colorectal cancer patients: a real practice study with long-term outcome and prognostic factors
}

\begin{abstract}
Alessandro Ottaiano ${ }^{1, *}$, Valerio Scotti ${ }^{2, *}$, Chiara De Divitiis ${ }^{3}$, Monica Capozzi ${ }^{3}$, Carmen Romano ${ }^{3}$, Antonino Cassata ${ }^{3}$, Rossana Casaretti ${ }^{3}$, Lucrezia Silvestro ${ }^{3}$, Anna $\mathrm{Nappi}^{3}$, Valeria Vicario ${ }^{3}$, Alfonso De Stefano ${ }^{3}$, Salvatore Tafuto ${ }^{3}$, Massimiliano Berretta $^{4}$, Guglielmo Nasti ${ }^{1}$ and Antonio Avallone ${ }^{3}$

${ }^{1}$ Department of Abdominal Oncology, SSD-Innovative Therapies for Abdominal Metastases, Istituto Nazionale Tumori di Napoli G. Pascale IRCCS, National Cancer Institute, 80131, Naples, Italy

${ }^{2}$ San Rossore Clinic, Viale delle Cascine, 56122, Pisa, Italy

${ }^{3}$ Department of Abdominal Oncology, Experimental Clinical Oncology, Istituto Nazionale Tumori di Napoli G. Pascale IRCCS, National Cancer Institute, 80131, Naples, Italy

${ }^{4}$ Department of Medical Oncology, CRO Aviano, National Cancer Institute, 33081, Aviano, Italy

*These authors have contributed equally to this work

Correspondence to: Guglielmo Nasti, email: g.nasti@istitutotumori.na.it, ale.otto@libero.it

Keywords: colorectal cancer; radiation therapy; chemotherapy; metastatic colorectal cancer

Received: April 26, $2018 \quad$ Accepted: June 23, $2018 \quad$ Published: October 16, 2018

Copyright: Ottaiano et al. This is an open-access article distributed under the terms of the Creative Commons Attribution License 3.0 (CC BY 3.0), which permits unrestricted use, distribution, and reproduction in any medium, provided the original author and source are credited.
\end{abstract}

\section{ABSTRACT}

Background: There are very few clinical or prognostic studies on the role of SRT (Stereotactic Radiation Therapy) in the continuum of care of metastatic colorectal cancer ( $\mathrm{MCRC}$ ) patients.

Patients and methods: Patients affected by oligo-mCRC were treated with SRT before or after front-line standard treatments. SRT was delivered according to a risk-adapted protocol. Total body CT (Computed Tomography) scan was done before therapy and every three months thereafter. The radiologic responses to therapy were evaluated by RECIST (Response Evaluation Criteria In Solid Tumors). FDG-PET (FluoroDeoxyGlucose - Positron Emission Tomography) was done before and after SRT; metabolic responses were evaluated by using the EORTC (European Organization for Research and Treatment of Cancer) criteria. The Kaplan-Meier product limit method was applied to graph Overall Survival (OS) and Progression-Free Survival (PFS).

Results: Forty-seven patients were included. Twenty-one patients had disease limited to lungs, 9 to lung and liver, 7 only to liver, 10 to multiple sites. The median prescription SRT dose was 60 Gy per organ in 3 fractions (median biological effective dose of $180 \mathrm{~Gy}$ ). The reduction of delta SUVmax (maximum Standardized Uptake Value) correlated with the local control $(p<0.001)$ and two-years survival $(p=0.003)$. At univariate analysis, localization of primary tumor, site of metastases, KRAS (Kirsten RAt Sarcoma) oncogene mutational status, response to first-line chemotherapy, response to SRT and number of treated lesions predicted both PFS and OS.

Discussion: This real practice experience suggests that further studies are needed to analyze the promising role of SRT in the multidisciplinary management of $\mathrm{mCRC}$. 


\section{INTRODUCTION}

Colorectal cancer is the third most common cancer worldwide. Despite progresses in the screening allowing for early diagnosis and definitive surgical removing of the localized tumors, about $30 \%$ of patients presents with advanced disease involving liver in more than $50 \%$ of cases [1]. Other organs frequently targeted by metastatic colorectal cancer (mCRC) are lungs and lymphnodes. The mainstay of pluri-mCRC treatment is chemotherapy (fluoropyrimidines, irinotecan, oxaliplatin) in association with new biologic drugs (bevacizumab, aflibercept, cetuximab and panitumumab); these drugs have improved survival reaching a median survival of about 30 months in selected patients [2].

In last years, the management of advanced disease has been enriched of integrated strategies including SRT (Stereotactic Radiation Therapy). The administration of SRT demonstrated, particularly in oligo-metastatic disease, to be a safe and effective option [3]. A definition of oligo-metastatic disease is the cancer spreading beyond the primary tumor involving one to three lesions per organ with a cumulative maximum tumor diameter per organ smaller than $7 \mathrm{~cm} \mathrm{[4].}$ However, oligo-metastatic disease is a dynamic and biologic state of cancer rather than the simple number and/or volume of the lesions so that its definition is difficult to approach and depends also on the instrumental tools used for detection [5]. Further molecular and biological markers identifying oligometastatic disease are urgently needed.

Many factors prompt the integration of SRT in the multidisciplinary therapeutic management of mCRC: i) the radiosensitivity of colorectal cancer, ii) the reduced toxicity (sparing of healthy tissue, high and hypofractionated irradiation doses) with the intriguing possibility of concomitant therapies, iii) the potential to induce immune system modulation with regression of tumor deposits in non-irradiated regions (abscopal effect), iv) the increasing availability of the technique. Several studies suggested a significant survival increase versus historical controls in patients bearing lung metastases with two-years survivals ranging from $67.7 \%$ to $77.0 \%$ and medians surpassing 30 months [6-8]. The most important prognostic factors were the number and volume of metastatic lesions. However, there are neither prospective nor randomized studies comparing SRT versus standard therapies.

Here we report the outcome of 47 patients treated from 2007 to 2012 with SRT for mCRC; the majority of patients had oligo-metastatic disease. In half of the cases the disease involved multiple sites (lungs, liver and/or abdominal lymphnodes).

\section{RESULTS}

\section{Patients, disease and treatment characteristics}

Patients, diseases and treatment characteristics are shown in Table 1. Median age of patients was 67 years (range: 45-81). Twenty-seven patients were male, 20 female. Most of patients had a PS ECOG 0,12 PS ECOG 1, 4 PS ECOG 2. The most common primary site was the left colon (15 patients), followed by right colon (10) and sigma (8). Twenty-one patients had disease limited to lungs, 9 to lung and liver, 7 only to liver; ten patients had also metastases to abdominal lymphnodes $(>15 \mathrm{~mm}$ at TC scan and SUV $>3$ at PET scan). Twenty-nine tumors had wild-type KRAS, 18 mutated. Twenty-nine patients underwent to front-line SRT; in 18 patients SRT was performed after a first-line chemotherapy. Thirty-five patients were treated with more than one line of SRT [at the same sites (re-irradiation) or at different sites].

\section{SRT according to metastatic sites}

In Table 2 we show the detailed extent of disease per patient at first-line SRT treatment. Most of patients had technically resectable oligo-metastatic disease (29 patients); however, they refused surgery (16 patients, two of them relapsed after previous lung metastasectomies) or had comorbidities (13 patients) (renal failure and/ or cardiac diseases and/or hepatic diseases, etc.) contraindicating metastasectomies or aggressive frontline chemotherapies (4 out of these patients did not receive chemotherapy, 2 received capecitabine and bevacizumab at reduced doses, 7 capecitabine and oxaliplatin at reduced doses). The SRT treatment was well tolerated; only three patients experienced persistent cough for 20 to 40 days after the last irradiation.

\section{Systemic treatments and toxicities}

Treatments are depicted in details in Table 3. Forty-three patients received a first-line chemotherapy; the most common schedule was the association between fluoropyrimidines (capecitabine or fluorouracil), oxaliplatin and bevacizumab (Capox or Folfox plus Bevacizumab). Median duration of treatments was 7.3 months. Four patient did not undergo to chemotherapy because of comorbidities and age. The use of fluoropyrimidines, irinotecan and anti-EGFR (cetuximab or panitumumab) was predominant in second-line therapies. Monotherapies with anti-EGFR agents and fluoropyrimidines and mitomycin-c association were more frequent in third-line treatments. Twenty-one patients were re-treated with previous therapies (if the progressionfree interval was more than 6 months and there were not previous grade 3/4 toxic events). There were no grade 4 toxicities or toxic deaths. The most common G3 adverse events were diarrhea (13/47 patients), neutropenia (11/47 patients) and cutaneous rush (6/47).

\section{Associations between SRT and clinical variables}

In our series, all patients performed FDG-PET before and after the first administration of SRT. Figure 1 
Table 1: Characteristics of patients and disease

\section{Characteristics}

Age, years

Median

Range

\section{Gender}

Male

Female

\section{Performance Status}

0

1

2

Site of primary tumor

Rectum

Sigma

Left colon

Trasversum

Right colon

Cecum

No.

31

12

4

8

15

6

10

3
Site of metastases

Only lung

Only liver

Lung and liver

Lung and abdominal lymphnodes

Liver and abdominal lymphnodes

\section{KRAS mutational status}

Wilde-type

Mutated

No. of systemic treatments before first-line SRT

0

1

No. of SRT lines

1 
Table 2: Distribution of metastatic lesions and reasons for performing SRT treatment

\begin{tabular}{|c|c|c|c|c|}
\hline $\begin{array}{l}\text { Patient } \\
\text { identification } \\
\text { number }\end{array}$ & $\begin{array}{l}\text { Oligometastatic } \\
\text { disease } a b \text { initio }\end{array}$ & Reasons for first-line SRT & $\begin{array}{c}\text { Distribution of lesions } \\
\text { at first SRT }\end{array}$ & $\begin{array}{c}\text { Total number of } \\
\text { lesions }\end{array}$ \\
\hline 1 & No & NA & 3 lung, 2 liver & 5 \\
\hline 2 & Yes & Refusal of metastasectomies & 3 lung & 3 \\
\hline 3 & Yes & Refusal of metastasectomies & 1 lung, 2 liver ${ }^{\mathrm{B}}$ & 3 \\
\hline 4 & Yes & Comorbidities & 3 lung, 2 abdominal LN & 5 \\
\hline 5 & Yes & Refusal of metastasectomies & 2 liver & 2 \\
\hline 6 & No & NA & 2 lung & 2 \\
\hline 7 & No & NA & 4 lung & 4 \\
\hline 8 & Yes & Refusal of metastasectomies & 2 lung & 2 \\
\hline 9 & Yes & Refusal of metastasectomies & 3 liver & 3 \\
\hline 10 & No & NA & 2 lung, 2 liver & 4 \\
\hline 11 & Yes & Refusal of metastasectomies & 3 lung & 3 \\
\hline 12 & No & NA & 3 lung, 2 abdominal LN & 5 \\
\hline 13 & Yes & Comorbidities & 6 lung & 6 \\
\hline 14 & Yes & Refusal of metastasectomies & 2 lung, 1 abdominal LN & 3 \\
\hline 15 & No & NA & 2 liver, 2 abdominal LN & 4 \\
\hline 16 & Yes & Refusal of metastasectomies & 3 liver $^{\mathrm{B}}$ & 3 \\
\hline 17 & Yes & Refusal of metastasectomies & 1 lung & 1 \\
\hline 18 & No & NA & 2 lung & 2 \\
\hline 19 & Yes & Comorbidities & 3 liver, 2 abdominal LN & 5 \\
\hline 20 & Yes & Comorbidities & 4 liver $^{\mathrm{B}}$ & 4 \\
\hline 21 & Yes & Refusal of metastasectomies & 2 lung & 2 \\
\hline 22 & No & NA & 3 lung, 1 abdominal LN & 4 \\
\hline 23 & No & NA & 5 lung & 5 \\
\hline 24 & No & NA & 4 lung & 4 \\
\hline 25 & Yes & Comorbidities & 2 lung, 1 abdominal LN & 3 \\
\hline 26 & Yes & Comorbidities & 3 liver, 2 abdominal LN & 5 \\
\hline 27 & Yes & Refusal of metastasectomies & 2 lung & 2 \\
\hline 28 & No & NA & 4 lung, 3 liver & 7 \\
\hline 29 & Yes & Comorbidities & 2 lung, 1 liver & 3 \\
\hline 30 & Yes & Refusal of metastasectomies & 3 liver $^{\mathrm{B}}$ & 3 \\
\hline 31 & Yes & Comorbidities & 5 liver & 5 \\
\hline 32 & Yes & Comorbidities & 4 lung, 2 liver & 6 \\
\hline 33 & No & NA & 3 lung & 3 \\
\hline 34 & Yes & Refusal of metastasectomies & 1 lung, 1 liver & 2 \\
\hline 35 & Yes & Comorbidities & 6 lung & 6 \\
\hline \multirow[t]{2}{*}{36} & Yes & Refusal of metastasectomies & 3 lung & 3 \\
\hline & & & & (continued) \\
\hline
\end{tabular}




\begin{tabular}{lcccc}
\hline $\begin{array}{l}\text { Patient } \\
\text { identification } \\
\text { number }\end{array}$ & $\begin{array}{c}\text { Oligometastatic } \\
\text { disease } \boldsymbol{a b} \text { initio }\end{array}$ & Reasons for first-line SRT & $\begin{array}{c}\text { Distribution of lesions } \\
\text { at first SRT }\end{array}$ & $\begin{array}{c}\text { Total number of } \\
\text { lesions }\end{array}$ \\
\hline $\mathbf{3 7}$ & No & NA & 2 lung & 2 \\
$\mathbf{3 8}$ & No & NA & 5 lung, 2 abdominal LN & 7 \\
$\mathbf{3 9}$ & Yes & Refusal of metastasectomies & 2 lung & 2 \\
$\mathbf{4 0}$ & Yes & Comorbidities & 3 lung, 1 abdominal LN & 4 \\
$\mathbf{4 1}$ & No & NA & 5 lung & 5 \\
$\mathbf{4 2}$ & Yes & Refusal of metastasectomies & 1 lung & 1 \\
$\mathbf{4 3}$ & Yes & Comorbidities & 3 lung, 3 liver & 6 \\
$\mathbf{4 4}$ & No & NA & 3 lung & 3 \\
$\mathbf{4 5}$ & No & NA & 2 lung & 2 \\
$\mathbf{4 6}$ & Yes & Comorbidities & 3 liver & 3 \\
$\mathbf{4 7}$ & No & NA & 4 lung, 3 liver & 7 \\
\hline
\end{tabular}

NA: Not Applicable, in these cases SRT was performed after chemotherapy for poly-metastatic disease on "residual" masses.

${ }^{\mathrm{B}}$ These patients experienced progressive disease at first-line chemotherapy.

shows FDG-PET results of SRT in three patients. The median prescription dose was 60 Gy per organ in 3 fractions (median biological effective dose of $180 \mathrm{~Gy}$ ). The reduction of deltaSUV $\mathrm{max}_{\text {max }}$ correlated with the local control of disease (time-to-progression after SRT at the irradiated sites, $\mathrm{p}<0.001)$ and survival at two years $(\mathrm{p}=0.003)$. Interestingly, although not significant $(\mathrm{p}=0.0512)$ for the low numbers included, patients who received a first-line chemotherapy including bevacizumab (anti-VEGF) before SRT were more prone to respond to SRT compared to patients treated with chemotherapy only. There were no significant correlations between delta SUVmax (maximum Standardized Uptake Value)and timing of chemotherapy (before or after SRT), response to first-line treatment, and sites of disease (Table 4). Given the importance of the metastatic site in the decision-making and planning of SRT, with an exploratory and descriptive aim, potential correlations between sites of disease and FDG-PET responses after SRT were studied (Table 5a and 5b). The patients were divided into two groups: i) upfront SRT $v s$ ii) SRT after front-line chemotherapy. In fact, in the second group, responses to SRT could be influenced by the previous exposition of neoplastic cells to chemotherapy. There were no significant differences in terms of FDGPET responses to SRT between different sites into the two groups; however, most of CMR and PMR according to EORTC criteria were observed in lung-limited disease patients

\section{Clinical and pathological prognostic factors in patients treated with SRT}

One of the most important characteristic of our series is the mature follow-up (median follow-up: 48.8 months); forty-five events were registered, only two patients are still alive at the time of last follow-up (May, 16 2017). The median PFS of the entire series was 16 months; median OS 44.0 months. Figure 2 and 3 show Kaplan-Meyer PFS and OS curves according to response to systemic therapy or SRT and extent of the disease. At univariate analysis, localization of primary tumor, site of metastases, KRAS mutational status, response to first-line chemotherapy, response to upfront SRT evaluated with FDG-PET and number of treated lesions had a positive prognostic power (Table 6 and 7).

\section{DISCUSSION}

Patients with mCRC may present with an oligometastatic disease with neoplastic lesions approachable with local treatments. In last years, many studies have been published reporting results of SRT in the treatment of oligo-mCRC [9-23]. They were heterogeneous in terms of number of treated patients (from 13 [17] to 82 [20]) and median overall survivals (from 16.0 months [10] to 46.0 [21]). Median follow-up was often inferior to 35 months with the longest one reported by Agolli et al. of 36 
Table 3: Chemotherapeutic regimens

\begin{tabular}{|c|c|}
\hline First-line schedules & No. of patients \\
\hline Folfox or Capox & 9 \\
\hline Folfox or Capox + Bevacizumab & 23 \\
\hline Folfiri or CapIri & 1 \\
\hline Folfiri or CapIri + Bevacizumab & 2 \\
\hline Folfiri or CapIri + anti-EGFR & 6 \\
\hline Irinotecan + anti-EGFR & 0 \\
\hline Fluoropyrimidines monotherapy & 0 \\
\hline Fluoropyrimidines + Bevacizumab & 2 \\
\hline Anti-EGFR monotherapy & 0 \\
\hline Fluoropyrimidines + Mytomicin-C & 0 \\
\hline \multicolumn{2}{|l|}{ Second-line schedules } \\
\hline Folfox or Capox & 7 \\
\hline Folfox or Capox + Bevacizumab & 0 \\
\hline Folfiri or CapIri & 8 \\
\hline Folfiri or CapIri + Bevacizumab & 2 \\
\hline Folfiri or CapIri + anti-EGFR & 15 \\
\hline Irinotecan + anti-EGFR & 4 \\
\hline Fluoropyrimidines monotherapy & 3 \\
\hline Fluoropyrimidines + Bevacizumab & 0 \\
\hline Anti-EGFR monotherapy & 1 \\
\hline Fluoropyrimidines + Mytomicin-C & 0 \\
\hline \multicolumn{2}{|l|}{ Third line schedules } \\
\hline Folfox or Capox & 1 \\
\hline Folfox or Capox + Bevacizumab & 0 \\
\hline Folfiri or CapIri & 3 \\
\hline Folfiri or CapIri + Bevacizumab & 0 \\
\hline Folfiri or CapIri + anti-EGFR & 0 \\
\hline Irinotecan + anti-EGFR & 3 \\
\hline Fluoropyrimidines monotherapy & 4 \\
\hline Fluoropyrimidines + Bevacizumab & 0 \\
\hline Anti-EGFR monotherapy & 6 \\
\hline Fluoropyrimidines + Mytomicin-C & 9 \\
\hline Re-challenges at any lines of therapy & 21 \\
\hline
\end{tabular}

months [15]. In our study we show the outcome as well as the prognostic factors of 47 consecutive patients affected by oligo-mCRC treated with first or subsequent lines of SRT from 2007 to 2012. Notably, most of patients had a local control $>12$ months, which is similar to previous experiences. Furthermore, the median overall survival in our series, including patients with both lung and liver involvement (9 patients) or diffusion to abdominal lymphnodes (10 patients) of 44.0 months, was particularly positive considering that the best survival previously 
reached with SRT (46.0 months) was reported in patients with only lung metastases [21]. Interestingly, the fiveyear survival of patients with lung-limited disease was $39 \%$, this data compares well with historical surgical controls [21-24] considering also that 12 patients had $\geq 3$ lesions and that some patients received a "depotentiated" chemotherapy course because of comorbidities or age.
The more positive outcome of our study could be attributable to the introduction of new therapies (antiVEGF, anti-EGFR agents) in the context of a continuum of care strategy. However, many patients had comorbidities excluding the administration of standard or continuous chemotherapies. A possible speculative explanation of significantly better results can rely also on different lines

A1
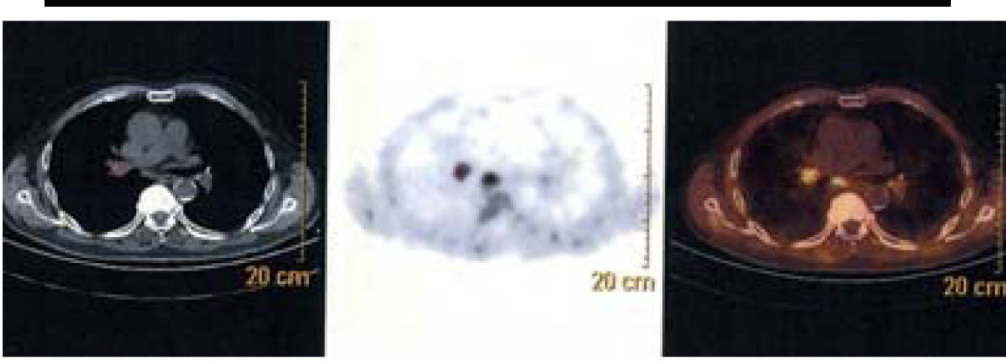

A2
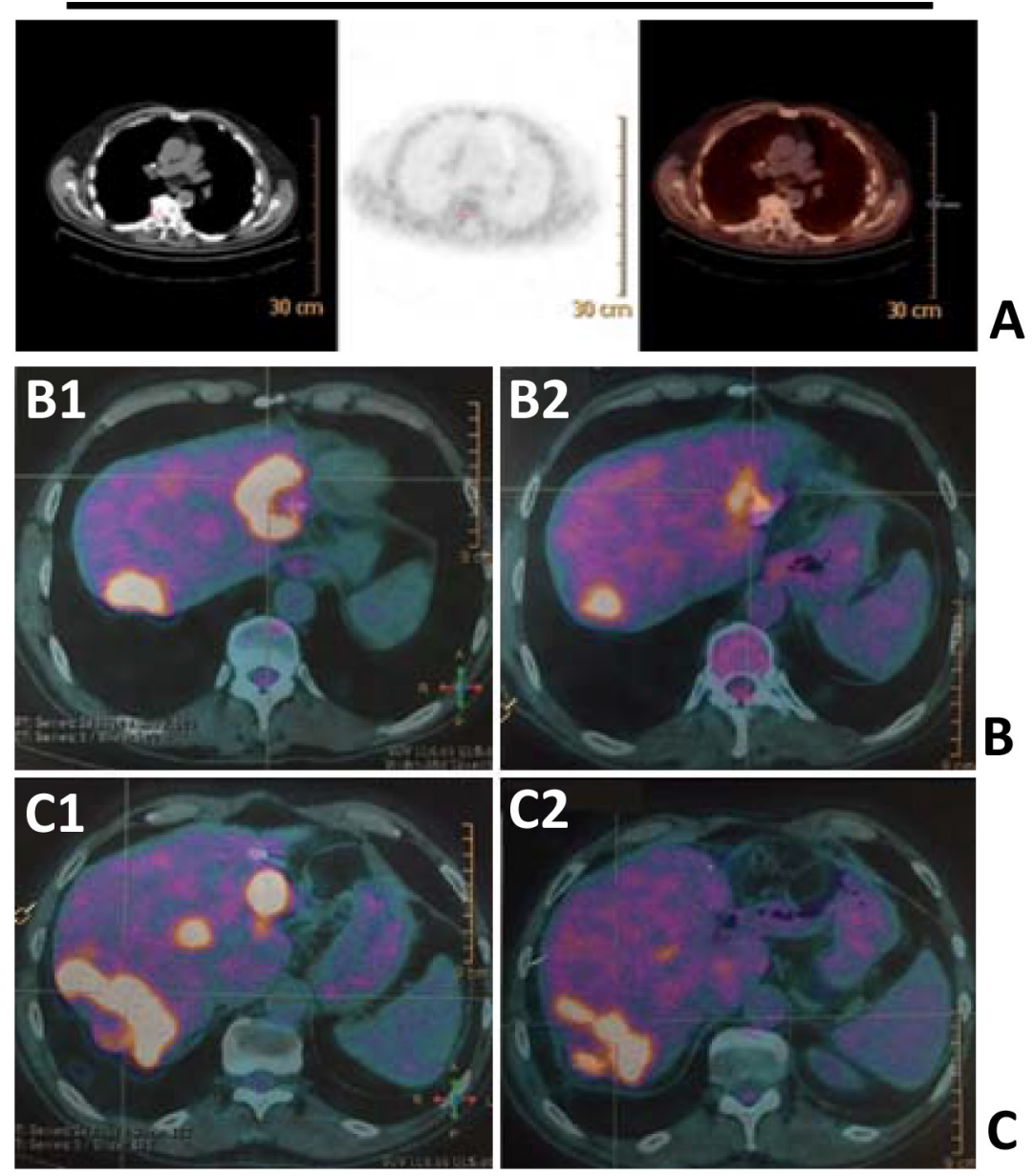

Figure 1: FDG-PET scans showing FDG uptakes before (A1, B1 and C1) and after SRT (A2, B2 and C2) in lungs (A1 vs A2) and liver metastases (B1 vs B2; C1 vs C2) of three patients (panels $\mathbf{A}, \mathbf{B}, \mathbf{C}$ ). 
Table 4: Correlations between $\Delta S U V_{\text {max }}$ and clinical variables

DSUV $_{\text {max }}$ median of the

No. of patients treated lesions (standard

deviation)

Local control (months) ${ }^{\mathrm{A}}$

$\begin{array}{lll}<6 & 10 & 42(28) \\ 6-12 & 12 & 62(18) \\ >12 & 25 & 78(23)\end{array}$

$<0.001$

Chemotherapy before SRT

$\begin{array}{ll}\text { No } & 29\end{array}$

64 (16)

Yes

18

68 (22)

0.293

Response to first-line chemotherapy
RC, RP, SD
37
69 (26)
PD
6
62 (19)
0.348

Anti-VEGF therapy before SRT

Yes

No

11

5

Overall survival

$\leq 2$ years

$>2$ years

Sites of disease

Lung

Liver

Lung and liver

Presence of LN metastases

\section{KRAS mutational status}

Wilde Type

Mutated

18
73 (15)

$56(20)$

0.0512

46 (17)

75 (22)

0.003

67 (16)

58 (28)

$71(15)$

77 (20)

0.091

69 (14)

61 (19)

0.462

A: from the date of the first SRT application to the evidence of progression of the irradiate site.

Table 5a: FDG-PET responses in patients receiving upfront SRT (29 patients)

\begin{tabular}{|c|c|c|c|c|c|}
\hline & & \multicolumn{4}{|c|}{ FDG-PET response } \\
\hline & & CMR & PMR & SMD & PMD \\
\hline \multicolumn{6}{|l|}{ Sites of disease } \\
\hline Lung & 11 & 1 & 7 & 2 & 1 \\
\hline Liver & 7 & 2 & 4 & 0 & 1 \\
\hline Lung and liver & 5 & 0 & 2 & 1 & 2 \\
\hline Presence of LN metastases & 6 & 1 & 1 & 2 & 1 \\
\hline
\end{tabular}


Table 5b: FDG-PET responses in patients receiving SRT after first-line line chemotherapy (18 patients)

\begin{tabular}{|c|c|c|c|c|c|}
\hline & & \multicolumn{4}{|c|}{ FDG-PET response } \\
\hline & & CMR & PMR & SMD & PMD \\
\hline \multicolumn{6}{|l|}{ Sites of disease } \\
\hline Lung & 10 & 2 & 6 & 2 & 0 \\
\hline Liver & 0 & 0 & 0 & 0 & 0 \\
\hline Lung and liver & 4 & 0 & 2 & 1 & 1 \\
\hline Presence of LN metastases & 4 & 0 & 2 & 0 & 2 \\
\hline
\end{tabular}

CMR: complete metabolic response; PMR: partial metabolic response; SMD: stable metabolic disease; PMD: progressive metabolic disease.

*All PMDs were attributable to new lesions distant form the irradiated sites.

of SRT (re-irradiations) reinforcing the abscopal effect of radiotherapy which consists on the local induction of tumor antigens and the release of cytokines stimulating in turn the innate and adaptive immunity [25]. However, this is a perspective to verify because in the present study, no immunologic evaluations were done. In future studies, prospective evaluations of immune-regulatory cells (Tregs [regulatory T cells], MDSC [myeloid-derived suppressor cells]) [26], effector cells (NK [Natural Killer] and T lymphocytes) [27], cytokines [28] and correlations with immunescores $[29,30]$ (on primary and/or metastatic lesions) will be necessary to clarify the immunologic
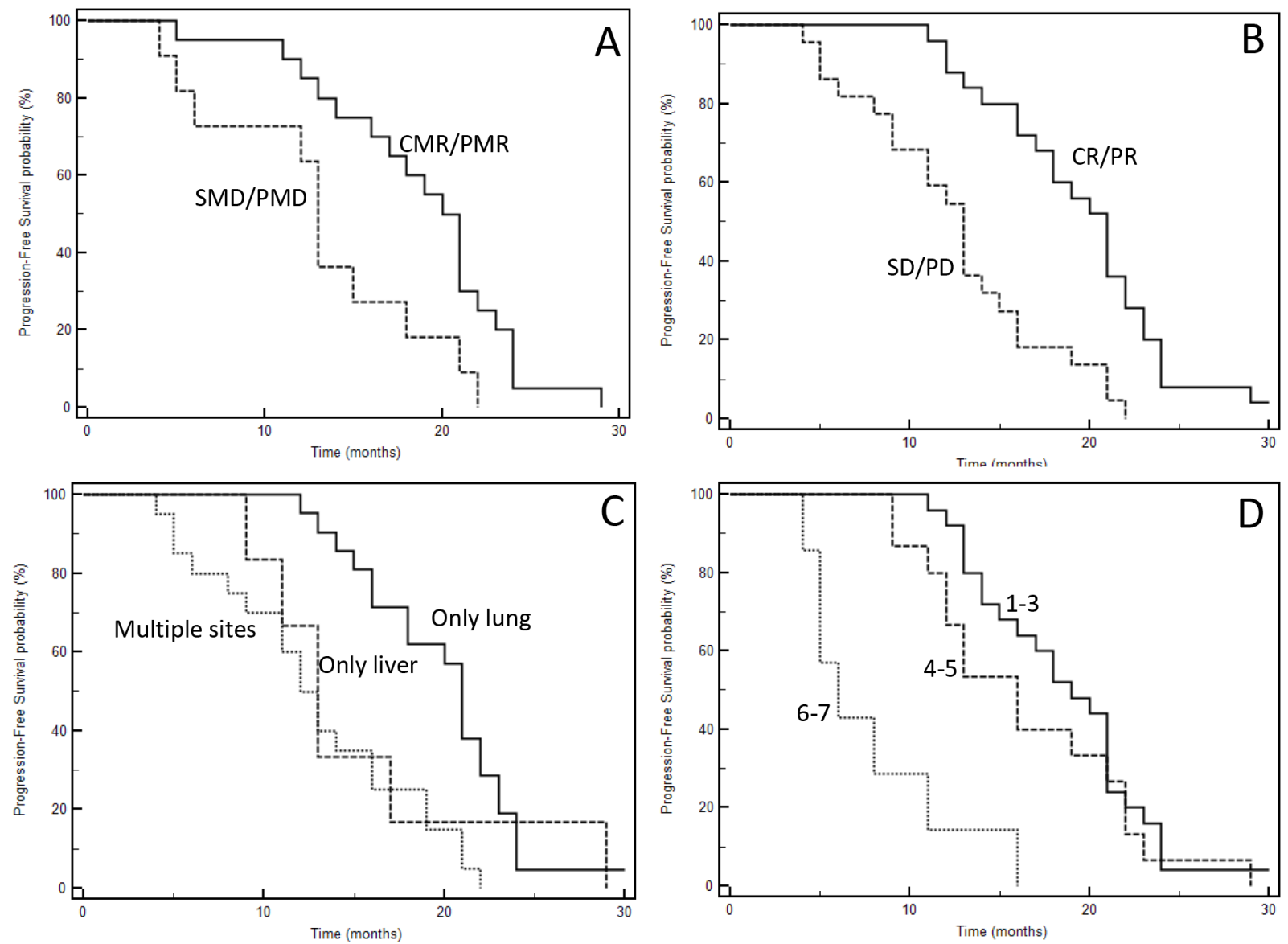

Figure 2: Kaplan-Meyer progression-free survival curves according to response to therapies (A: SRT; B: chemotherapy), and extent of disease (C: type of involved organ; D: total number of metastases). See Table 6 for P at log-rank test. 
mechanisms eventually underling the clinical outcomes. However, to this regard, many clinical and translational trials in advanced lung, melanoma and mCRC are now recruiting patients through protocols based on SRT and immunotherapies with different mechanisms of action (pembrolizumab, durvalumab, tremelimumab, dabrafenib, trametinib, MK-3475, etc.) (https://clinicaltrials.gov/). The intent of these studies is to take advantage from the immune-modulating properties of SRT in synergism with immunotherapeutic drugs to improve the anti-tumor effects.

Interestingly, some patients presented with polymetastatic multi-organs disease and received a standard first-line chemotherapy as front-line therapy; in these cases, SRT was administered in "residual" disease. These patients are more similar to mCRC patients with more aggressive and widely metastatic tumors. They did not receive systemic therapy after SRT until progression. The univariate analysis showed a worse prognosis compared to patients with only lung or liver involvement; however, they had a median survival of 34 months which is superior to the survival described in last generation randomized trials $[31,32]$. Lacking specific studies (ideally, chemotherapy plus SRT vs chemotherapy), this is an indirect evidence that the integration of SRT in advanced disease could ameliorate the anti-neoplastic effect of chemotherapy and contribute to the control of systemic disease.

The neoplastic lesions responded to SRT independently from i) the primary or metastatic site, ii) the administration of upfront chemotherapy, iii) chemosensitivity of the tumor (evaluated as response to a first-line chemotherapy). Interestingly, the administration of bevacizumab before irradiation was slightly associated with the metabolic response $(p=0.0512)$. Although not significant, this could be related to the effect of bevacizumab on tumor vasculature with reduction in microvessel density producing an increase of tumor oxygenation and perfusion; these phenomena are associated with increased sensitivity to radiation therapy in tumor models $[33,34]$.

KRAS mutational status was not associated with response to SRT, but predicted PFS and OS at univariate analysis. The best prognostic profile in this study was represented by left sided, KRAS wild-type, lung-limited tumor. The presence of these three conditions were strongly associated with survival compared to other
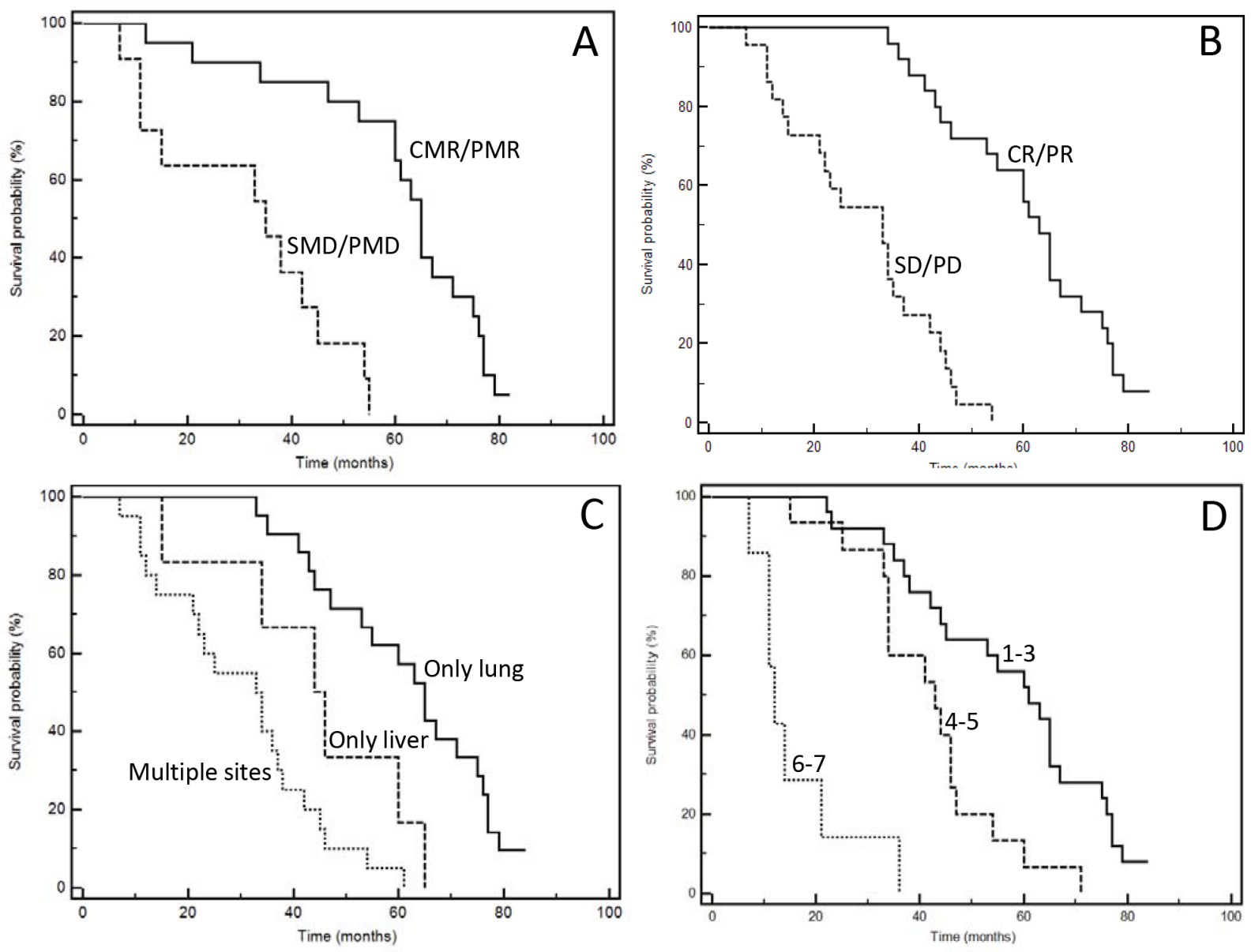

Figure 3: Kaplan-Meyer survival curves according to response to therapies (A: SRT; B: chemotherapy), and extent of disease (C: type of involved organ; D: total number of metastases). See Table 7 for P at log-rank test. 
Table 6: Univariate analysis of progression-free survival according to specific clinical, molecular and anatomical variables

\begin{tabular}{|c|c|c|c|c|c|}
\hline Variable & Events/Patients & $\begin{array}{c}\text { Median PFS } \\
\text { (months) }\end{array}$ & $\mathbf{H R}^{2}$ & $95 \% \mathrm{CI}^{3}$ & $P$ at univariate \\
\hline $\begin{array}{l}\text { Age }(\leq 70 \text { vs }>70 \\
\text { years })\end{array}$ & $15 / 16$ vs $31 / 31$ & 16 vs 16 & 1.29 & $0.71-2.34$ & 0.37 \\
\hline $\begin{array}{l}\text { Gender (male vs } \\
\text { female) }\end{array}$ & $26 / 27$ vs $20 / 20$ & 14 vs 20 & 0.86 & $0.48-1.53$ & 0.57 \\
\hline $\begin{array}{l}\text { Localization of } \\
\text { primary tumor } \\
\text { (right vs left } \\
\text { colon) }\end{array}$ & $24 / 24$ vs $22 / 23$ & 13 vs 19 & 1.70 & 0.94-3.09 & 0.0445 \\
\hline $\begin{array}{l}\text { Site of } \\
\text { metastases (only } \\
\text { lung vs only } \\
\text { liver vs multiple } \\
\text { sites) }\end{array}$ & $\begin{array}{c}20 / 21 \text { vs } 6 / 6 \text { vs } \\
20 / 20\end{array}$ & 21 vs 13 vs 12 & 0.36 & $0.18-0.73$ & 0.0014 \\
\hline $\begin{array}{l}\text { KRAS } \\
\text { mutational status } \\
\text { (mutated vs } \\
\text { wild-type) }\end{array}$ & $18 / 18$ vs $28 / 29$ & 12 vs 18 & 2.02 & $1.02-3.97$ & 0.0093 \\
\hline $\begin{array}{l}\text { Response } \\
\text { to first-line } \\
\text { chemotherapy } \\
\text { (RC/RP vs SD/ } \\
\text { PD) }\end{array}$ & $25 / 26$ vs $21 / 21$ & 21 vs 13 & 0.35 & $0.18-0.69$ & $<0.0001$ \\
\hline $\begin{array}{l}\text { Response to } \\
\text { first-line SRT } \\
\text { (CMR/PMR vs } \\
\text { SMD/PMD) }\end{array}$ & $20 / 20$ vs $11 / 11$ & 20 vs 13 & 0.43 & $0.17-1.05$ & 0.0199 \\
\hline $\begin{array}{l}\text { Number of } \\
\text { lesions ( } 1-3 \text { vs } \\
4-5 \text { vs } 6-7)\end{array}$ & $\begin{array}{c}24 / 25 \text { vs } 15 / 15 \\
\text { vs } 7 / 7\end{array}$ & 19 vs 16 vs 6 & 0.14 & $0.02-0.85$ & $<0.0001$ \\
\hline
\end{tabular}

$\mathrm{PFS}^{1}=$ Progression-Free Survival; $\mathrm{HR}^{2}=$ Hazard Ratio; $\mathrm{CI}^{3}=$ Confidence Intervals.

Table 7: Univariate analysis of overall survival according to specific clinical, molecular and anatomical variables

\begin{tabular}{|c|c|c|c|c|c|}
\hline Variable & Events/Patients & $\begin{array}{l}\text { Median OS } \\
\text { (months) }\end{array}$ & $\mathbf{H R}^{2}$ & $95 \% \mathrm{CI}^{3}$ & $P$ at univariate \\
\hline $\begin{array}{l}\text { Age }(\leq 70 \text { vs }>70 \\
\text { years })\end{array}$ & $14 / 16$ vs $31 / 31$ & 41.5 vs 46 & 1.28 & $0.69-2.35$ & 0.42 \\
\hline $\begin{array}{l}\text { Gender (male vs } \\
\text { female) }\end{array}$ & $25 / 27$ vs $20 / 20$ & 44 vs 45 & 0.97 & $0.54-1.75$ & 0.92 \\
\hline $\begin{array}{l}\text { Localization of } \\
\text { primary tumor } \\
\text { (right vs left } \\
\text { colon) }\end{array}$ & $19 / 19$ vs $26 / 28$ & 38 vs 60 & 2.03 & $1.11-4.68$ & 0.0008 \\
\hline
\end{tabular}




\begin{tabular}{|c|c|c|c|c|c|}
\hline Variable & Events/Patients & $\begin{array}{l}\text { Median OS } \\
\text { (months) }\end{array}$ & $\mathbf{H R}^{2}$ & $95 \% \mathrm{CI}^{3}$ & $P$ at univariate \\
\hline $\begin{array}{l}\text { Site of } \\
\text { metastases (only } \\
\text { lung vs only } \\
\text { liver vs multiple } \\
\text { sites) }\end{array}$ & $\begin{array}{c}19 / 21 \text { vs } 6 / 6 \text { vs } \\
20 / 20\end{array}$ & 65 vs 45 vs 33 & 0.28 & $0.15-0.55$ & $<0.0001$ \\
\hline $\begin{array}{l}\text { KRAS } \\
\text { mutational status } \\
\text { (mutated vs } \\
\text { wild-type) }\end{array}$ & $18 / 18$ vs $27 / 29$ & 34 vs 55 & 2.47 & $1.21-5.05$ & 0.0012 \\
\hline $\begin{array}{l}\text { Response } \\
\text { to first-line } \\
\text { chemotherapy } \\
\text { (RC/RP vs SD/ } \\
\text { PD) }\end{array}$ & $24 / 26$ vs $21 / 21$ & 63 vs 33 & 0.23 & $0.10-0.49$ & $<0.0001$ \\
\hline $\begin{array}{l}\text { Response to } \\
\text { first-line SRT } \\
\text { (CMR/PMR vs } \\
\text { SMD/PMD) }\end{array}$ & $19 / 20$ vs $11 / 11$ & 65 vs 35 & 0.22 & $0.07-0.69$ & $<0.0001$ \\
\hline $\begin{array}{l}\text { Number of } \\
\text { lesions (1-3 vs } \\
4-5 \text { vs } 6-7)\end{array}$ & $\begin{array}{c}23 / 25 \text { vs } 15 / 15 \\
\text { vs } 7 / 7\end{array}$ & 61 vs 43 vs 12 & 0.23 & $0.02-0.77$ & $<0.0001$ \\
\hline
\end{tabular}

$\mathrm{OS}^{1}=$ Overall Survival $; \mathrm{HR}^{2}=$ Hazard Ratio $\mathrm{CI}^{3}=$ Confidence Intervals.

prognostic combinations ( +33.5 months; 75.5 vs 42 months; HR: 0,30 ; $95 \%$ CI: $0.16-0.56$; $p=0.0021$ at logrank test) and with response to SRT and chemotherapy (data not shown).

One of the major limitation of our study consists on the heterogeneity of patient cohort with regard to systemic treatment protocols, radiotherapy regimens (doses and timing with chemotherapy) and Kras status that, in absence of a comparator (no SRT), makes interpretation of the findings as predominantly descriptive and exploratory. However, the increasing availability of SRT along with the shorter treatment duration, the high precision and the high sparing of surrounding normal tissues, make this technique a valid option in the treatment of oligo-mCRC; in left-sided, KRAS wild-type, lung-limited tumors it could be a valid alternative to surgery. Furthermore, our experience suggests that SRT could contribute to obtain a long-term disease control also when multiple organs are involved; prospective and larger studies are needed to confirm these data.

\section{MATERIALS AND METHODS}

\section{Patient management and follow-up}

Patients were treated at the Department of Abdominal Medical Oncology of the National Cancer
Institute (Naples, Italy) from 2007 to 2012. Only two patients of the present cohort did not undergo to primary tumor resection because it was asymptomatic. All primary tumors were routinely characterized for KRAS (Kirsten RAt Sarcoma) oncogene mutational status. Six patients were stage III at diagnosis but they presented distant metastases three months after surgery at the first follow-up (synchronous metastases). Sequential standard treatments with chemotherapy (fluorouracil/ capecitabine, irinotecan, oxaliplatin) and/or biologic therapies (bevacizumab, cetuximab, panitumumab) were administered. The choice of chemotherapy regimen was based on patient's performance status, extent of disease, comorbidities, previous treatments and individual preferences. Informed consent from each patient was sought. Total body computed tomography (CT) scan and CEA (CarcinoEmbryonic Antigen) monitoring were done every three months. The response to therapy was evaluated by RECIST (Response Evaluation Criteria In Solid Tumors). Patients with target metastatic lesions restaged at the Radiology Unit were considered for response evaluation. Complete response (CR) was defined as complete disappearance of all detectable evidence of disease on total body computed tomography. Partial response (PR) was defined as at least a $30 \%$ decrease in the sum of diameters of target lesions. Stable disease (SD) 
was defined as everything between 30\% decrease and $20 \%$ growth of tumor size. Progressive disease (PD) was defined as at least a $20 \%$ increase in the sum of diameters of target lesions. Toxicity was graded with the Common Toxicity Criteria for Adverse Events (CTCAE) v3.0. Local control was defined from last day of SRT to local relapse within the irradiated site. RECIST was only used to assess response to chemotherapy.

FDG-PET (FluoroDeoxyGlucose-Positron Emission Tomography) responses were evaluated by using the European Organization for Research and Treatment of Cancer (EORTC) criteria $[35,36]$. In brief, definitions of metabolic response by FDG-PET/CT included: complete metabolic response (CMR: complete resolution of all metabolically active target and non-target lesions, and no new lesions); partial metabolic response (PMR: 20\% or greater decrease in SUV of target lesions with or without decrease in number/size of nontarget lesions, and no new lesions); progressive metabolic disease (PMD: one or more new lesions, 20\% or greater increase in SUV of target lesions and/or unequivocal increase in FDG activity of nontarget lesions); and stable metabolic disease (SMD: not qualifying as CMR, PMR, or PMD). FDG PET responses were also evaluated with the Response Index (RI). The measurements of SUV (Standardized Uptake Value) obtained in the metastatic lesions at baseline $\left(\mathrm{SUV}_{1}\right)$ and after 60 days from SRT treatment $\left(\mathrm{SUV}_{2}\right)$ were compared and the change was expressed as the percentage of SUV reduction $\left(\Delta \mathrm{SUV}=\left(\mathrm{SUV}_{1}-\mathrm{SUV}_{2}\right) / \mathrm{SUV}_{1} \times 100\right)$.

\section{SRT indications}

Our policy was to propose SRT in patients with one to six lesions in the lungs, one to three lesions into the liver, with a cumulative maximum tumor diameter per organ smaller than $7 \mathrm{~cm}$ or in patients who refused surgery or had comorbidities contraindicating surgery or chemotherapy. The presence of metastatic abdominal lymphnodes (until 3) did not excluded SRT. However, the indication to perform SRT was discussed in a multidisciplinary context. Notably, in few cases the transition from poly- to oligo-metastatic disease was obtained after chemotherapy; these patients were reevaluated for SRT.

\section{SRT protocol}

SRT was delivered according to a risk-adapted protocol; doses and fractionations were based on the size and location of the tumor (54 Gy/3 fractions, $55 \mathrm{~Gy} / 5$ fractions or $60 \mathrm{~Gy} / 8$ fractions). Treatment was delivered on alternate days regardless of the dose-fractionation regimen. A 4-D CT simulation scan was acquired for all patients. Respiratory gating was considered in cases where motion was $>7 \mathrm{~mm}$ in any direction. The gross tumor volume (GTV) was defined as the visible tumor on CT and PET imaging, and an internal GTV encompassed the GTV from all phases of respiration. A planning target volume (PTV) margin of $5 \mathrm{~mm}$ was used. The prescription point was approximately the $80 \%$ isodose line surrounding the PTV, with the requirement that $95 \%$ of the PTV was covered by $100 \%$ of the prescription dose. FDG-PET was performed before SRT and after 60 days from the treatment end.

\section{Statistical analyses and data presentation}

Results of this study are predominantly descriptive and exploratory. Associations between responses to chemotherapy, SRT and clinical and pathologic variables (age, gender, oligo-metastatic disease, KRAS status, sites of disease) were evaluated by $\chi 2$ test. $\mathrm{P}<0.05$ was considered statistically significant. Progressionfree survival (PFS) was defined as the time elapsed from front-line treatment start to progression of the cancer as it occurred first; overall survival (OS) was defined as the time elapsed from the diagnosis to death from any cause. The Kaplan-Meier product limit method was applied to graph OS and PFS. Survival was measured from diagnosis in order to avoid generation of prognostic subgroups related to different treatments start times. Univariate analysis was done with the log-rank test. No attempt was done to perform multivariate analysis because of small number of cases. Statistical analysis was performed using the MedCalc ${ }^{\circledR}$ 9.3.7.0 and Excel software.

\section{CONFLICTS OF INTEREST}

The authors declare no conflicts of interest.

\section{REFERENCES}

1. Siegel R, Naishadham D, Jemal A. Cancer statistics, 2012. CA Cancer J Clin. 2012; 62: 10-29.

2. Nappi A, Berretta M, Romano C, Tafuto S, Cassata A, Casaretti R, Silvestro L, De Divitiis C, Alessandrini L, Fiorica F, Ottaiano A, Nasti G. Metastatic colorectal cancer: role of target therapies and future perspectives. Curr Cancer Drug Targets. 2018; 18:421-429. https://doi.org/10.2174/15 68009617666170209095143.

3. Lancia A, Ingrosso G, Carosi A, Di Murro L, Giudice E, Cicchetti S, Morelli P, di Cristino D, Bruni C, Murgia A, Cancelli A, Turturici I, Iadevaia A, et al. Oligometastatic cancer: stereotactic ablative radiotherapy for patients affected by isolated body metastasis. Acta Oncol. 2017; 56:1621-1625.

4. Rusthoven KE, Kavanagh BD, Burri SH, Chen C, Cardenes H, Chidel MA, Pugh TJ, Kane M, Gaspar LE, Schefter TE. Multi-Institutional Phase I/II Trial of Stereotactic Body Radiation Therapy for Lung Metastases. J Clin Oncol. 2009; 27: 1579-1584. 
5. Hellman S, Weichselbaum RR. Oligometastases. J Clin Oncol. 1995; 13: 8-10.

6. Filippi AR, Guerrera F, Badellino S, Ceccarelli M, Castiglione A, Guarneri A, Spadi R, Racca P, Ciccone G, Ricardi U, Ruffini E. Exploratory Analysis on Overall Survival after Either Surgery or Stereotactic Radiotherapy for Lung Oligometastases from Colorectal Cancer. Clin Oncol (R Coll Radiol). 2016; 28: 505-512.

7. Pasqualetti F, Montrone S, Vivaldi C, Zani M, Fedele D, Fornaro L, Pasqualetti G, Salvatore L, Manfredi B, Laliscia C, Coraggio G, Gonnelli A, Loupakis F, et al. Stereotactic Body Radiotherapy in Patients with Lung Oligometastases from Colorectal Cancer. Anticancer Res. 2017; 37: 315-319.

8. Agolli L, Bracci S, Nicosia L, Valeriani M, De Sanctis V, Osti MF. Lung Metastases Treated With Stereotactic Ablative Radiation Therapy in Oligometastatic Colorectal Cancer Patients: Outcomes and Prognostic Factors After Long-Term Follow-Up. Clin Colorectal Cancer. 2017; 16: 58-64.

9. Joo JH, Park JH, Kim JC, Yu CS, Lim SB, Park IJ, Kim TW, Hong YS, Kim KP, Yoon SM, Park J, Kim JH. Local Control Outcomes Using Stereotactic Body Radiation Therapy for Liver Metastases From Colorectal Cancer. Int J Radiat Oncol Biol Phys. 2017; 99: 876-883.

10. McPartlin A, Swaminath A, Wang R, Pintilie M, Brierley J, Kim J, Ringash J, Wong R, Dinniwell R, Craig T, Dawson LA. Long-Term Outcomes of Phase 1 and 2 Studies of SBRT for Hepatic Colorectal Metastases. Int J Radiat Oncol Biol Phys. 2017; 99: 388-395.

11. Franzese C, Fogliata A, Comito T, Tozzi A, Iftode C, Clerici E, Franceschini D, Navarria P, Ascolese AM, Di Brina L, De Rose F, D'Agostino GR, Cozzi L, Scorsetti M. Stereotactic/hypofractionated body radiation therapy as an effective treatment for lymph node metastases from colorectal cancer: an institutional retrospective analysis. Br J Radiol. 2017; 90: 20170422. https://doi.org/10.1259/ bjr.20170422.

12. Doi H, Uemoto K, Suzuki O, Yamada K, Masai N, Tatsumi D, Shiomi H, Oh RJ. Effect of primary tumor location and tumor size on the response to radiotherapy for liver metastases from colorectal cancer. Oncol Lett. 2017; 14: 453-460.

13. Kinj R, Bondiau PY, François E, Gérard JP, Naghavi AO, Leysalle A, Chamorey E, Evesque L, Padovani B, Ianessi A, Benezery K, Doyen J. Radiosensitivity of Colon and Rectal Lung Oligometastasis Treated With Stereotactic Ablative Radiotherapy. Clin Colorectal Cancer. 2017; 16: e211-e220.

14. Takeda A, Sanuki N, Tsurugai Y, Oku Y, Aoki Y. Stereotactic body radiotherapy for patients with oligometastases from colorectal cancer: risk-adapted dose prescription with a maximum dose of 83-100 Gy in five fractions. J Radiat Res. 2016; 57: 400-405.

15. Jung J, Song SY, Kim JH, Yu CS, Kim JC, Kim TW, Jeong SY, Kim SS, Choi EK. Clinical efficacy of stereotactic ablative radiotherapy for lung metastases arising from colorectal cancer. Radiat Oncol. 2015; 10: 238. https://doi. org/10.1186/s13014-015-0546-x.

16. Qiu H, Katz AW, Chowdhry AK, Usuki KY, Singh DP, Metcalfe S, Cheruvu P, Chen Y, Okunieff P, Milano MT. Stereotactic Body Radiotherapy for Lung Metastases from Colorectal Cancer: Prognostic Factors for Disease Control and Survival. Am J Clin Oncol. 2018; 41: 53-58.

17. Carvajal C, Navarro-Martin A, Cacicedo J, Ramos R, Guedea F. Stereotactic body radiotherapy for colorectal lung oligometastases: preliminary single-institution results. J BUON. 2015; 20: 158-165.

18. Filippi AR, Badellino S, Ceccarelli M, Guarneri A, Franco P, Monagheddu C, Spadi R, Ragona R, Racca P, Ricardi U. Stereotactic ablative radiation therapy as first local therapy for lung oligometastases from colorectal cancer: a singleinstitution cohort study. Int J Radiat Oncol Biol Phys. 2015; 91: 524-529.

19. Scorsetti M, Comito T, Tozzi A, Navarria P, Fogliata A, Clerici E, Mancosu P, Reggiori G, Rimassa L, Torzilli G, Tomatis S, Santoro A, Cozzi L. Final results of a phase II trial for stereotactic body radiation therapy for patients with inoperable liver metastases from colorectal cancer. J Cancer Res Clin Oncol. 2015; 141: 543-553.

20. Comito T, Cozzi L, Clerici E, Campisi MC, Liardo RL, Navarria P, Ascolese A, Tozzi A, Iftode C, De Rose F, Villa E, Personeni N, Rimassa L, et al. Stereotactic Ablative Radiotherapy (SABR) in inoperable oligometastatic disease from colorectal cancer: a safe and effective approach. BMC Cancer. 2014; 27; 14: 619. https://doi. org/10.1186/1471-2407-14-619.

21. Yokoyama S, Mitsuoka M, Kinugasa T, Hashiguchi T, Matsumoto R, Murakami D, Nishi T, Yoshiyama K, Kashihara M, Takamori S, Akagi Y. Survival after initial lung metastasectomy for metastatic colorectal cancer in the modern chemotherapeutic era. BMC Surg. 2017; 17: 54.

22. Kim JY, Park IJ, Kim HR, Kim DK, Lee JL, Yoon YS, Kim CW, Lim SB, Lee JB, Yu CS, Kim JC. Post-pulmonary metastasectomy prognosis after curative resection for colorectal cancer. Oncotarget. 2017; 8:36566-36577. https:// doi.org/10.18632/oncotarget.16616.

23. Nakajima J, Iida T, Okumura S, Horio H, Asamura H, Ozeki Y, Ikeda N, Matsuguma H, Chida M, Otsuka H, Kawamura M. Metastatic Lung Tumor Study Group of Japan. Recent improvement of survival prognosis after pulmonary metastasectomy and advanced chemotherapy for patients with colorectal cancer. Eur J Cardiothorac Surg. 2017; 51: 869-873.

24. Guerrera F, Mossetti C, Ceccarelli M, Bruna MC, Bora G, Olivetti S, Lausi PO, Solidoro P, Ciccone G, Ruffini E, Oliaro A, Filosso PL. Surgery of colorectal cancer lung metastases: analysis of survival, recurrence and re-surgery. J Thorac Dis. 2016; 8: 1764-1771.

25. Popp I, Grosu AL, Niedermann G, Duda DG. Immune modulation by hypofractionated stereotactic radiation 
therapy: Therapeutic implications. Radiother Oncol. 2016; 120: 185-194.

26. Tamadaho RSE, Hoerauf A, Layland LE. Immunomodulatory effects of myeloid-derived suppressor cells in diseases: Role in cancer and infections. Immunobiology. 2018; 223: 432-442.

27. Sun X, Suo J, Yan J. Immunotherapy in human colorectal cancer: Challenges and prospective. World J Gastroenterol. 2016; 22: 6362-6372.

28. Engel MA, Neurath MF. Anticancer properties of the IL-12 family--focus on colorectal cancer. Curr Med Chem. 2010; 17: 3303-3308.

29. Marks KM, West NP, Morris E, Quirke P. Clinicopathological, genomic and immunological factors in colorectal cancer prognosis. Br J Surg. 2018; 105: e99-e109.

30. El Sissy C, Marliot F, Haicheur N, Kirilovsky A, Scripcariu $\mathrm{D}$, Lagorce-Pagès $\mathrm{C}$, Galon $\mathrm{J}$, Pagès F. Focus on the Immunoscore and its potential clinicalimplications. Ann Pathol. 2017; 37: 29-38.

31. Heinemann V, von Weikersthal LF, Decker T, Kiani A, Vehling-Kaiser U, Al-Batran SE, Heintges T, Lerchenmüller C, Kahl C, Seipelt G, Kullmann F, Stauch M, Scheithauer $\mathrm{W}$, et al. FOLFIRI plus cetuximab versus FOLFIRI plus bevacizumab as first-line treatment for patients with metastatic colorectal cancer (FIRE-3): a randomised, openlabel, phase 3 trial. Lancet Oncol. 2014; 15: 1065-1075.
32. Cremolini C, Loupakis F, Antoniotti C, Lupi C, Sensi E, Lonardi S, Mezi S, Tomasello G, Ronzoni M, Zaniboni A, Tonini G, Carlomagno C, Allegrini G, et al. FOLFOXIRI plus bevacizumab versus FOLFIRI plus bevacizumab as first-line treatment of patients with metastatic colorectal cancer: updated overall survival and molecular subgroup analyses of the open-label, phase 3 TRIBE study. Lancet Oncol. 2015; 16: 1306-1315.

33. Myers AL, Williams RF, Ng CY, Hartwich JE, Davidoff AM. Bevacizumab-induced tumor vessel remodeling in rhabdomyosarcoma xenografts increases the effectiveness of adjuvant ionizing radiation. J Pediatr Surg. 2010; 45: 1080-1085.

34. McGee MC, Hamner JB, Williams RF, Rosati SF, Sims TL, Ng CY, Gaber MW, Calabrese C, Wu J, Nathwani AC, Duntsch C, Merchant TE, Davidoff AM. Improved intratumoral oxygenation through vascular normalization increases glioma sensitivity to ionizing radiation. Int $\mathrm{J}$ Radiat Oncol Biol Phys. 2010; 76: 1537-1545.

35. Gámez-Cenzano C, Pino-Sorroche F. Standardization and quantification in FDG-PET/CT imaging for staging and restaging of malignant disease. PET Clin. 2014; 9: 117-127.

36. Skougaard K, Nielsen D, Jensen BV, Hendel HW. Comparison of EORTC criteria and PERCIST for PET/CT response evaluation of patients with metastatic colorectal cancer treated with irinotecan and cetuximab. J Nucl Med. 2013; 54: 1026-1031. 